\title{
درجة فاعلية برامج أكاديمية الملكة رانيا في تأهيل المعلمين من وجهة نظر مديري مدارس لواء قصبة إربد
}

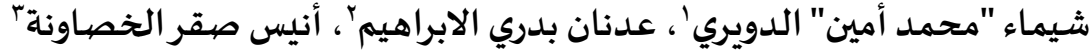

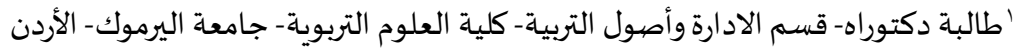

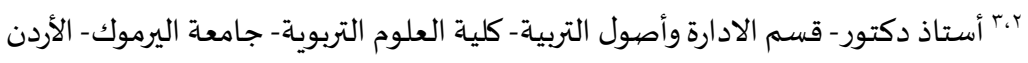 \\ 1Shaimadwery123@yahoo.com
}

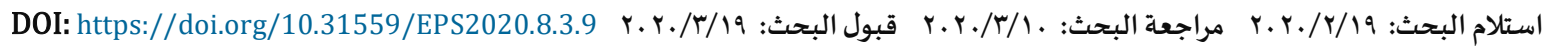

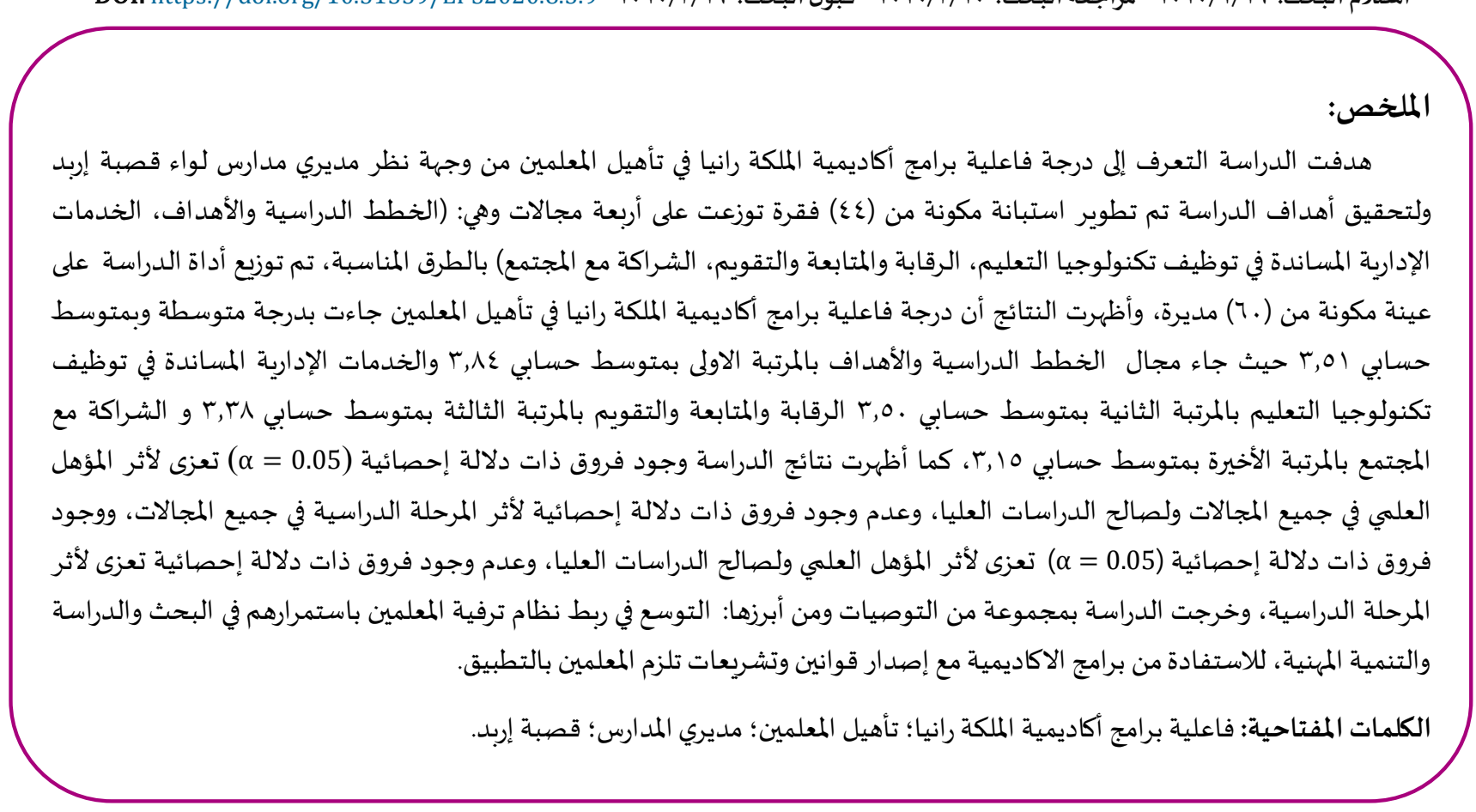

المقدمة:

في ظلل المنافسة العالمية والاقتصاد العالمي التكنولوجي وثورة المعلومات ازدادت أهمية تبني سياسات تربوية لتحسين جودة التعليم والتعلم، وعليه

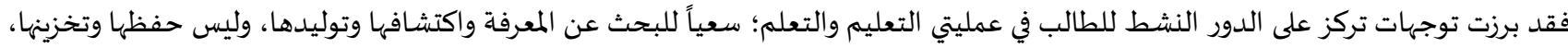

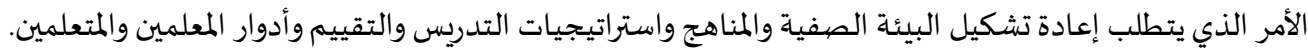

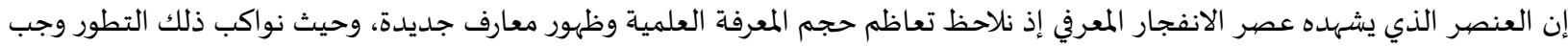

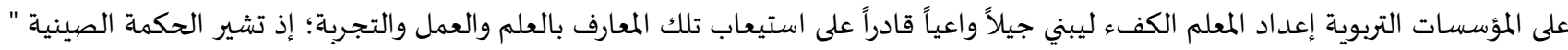

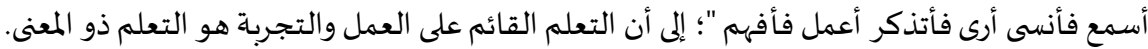

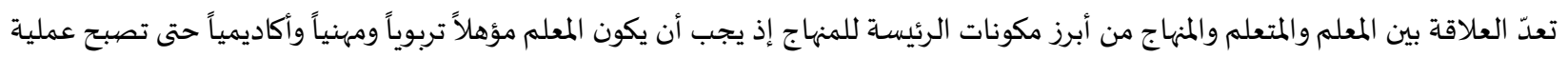

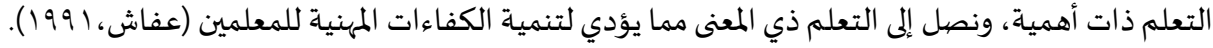


وحين أشارت دراسة فرانكز (Franks,2007) إلى تحديد فاعلية نموذج تديبي للمدربين في تنمية الكفاءة المهنية لمعلمي العلوم بالمرحلة الابتدائية

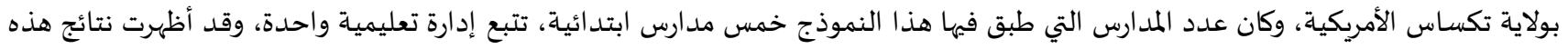

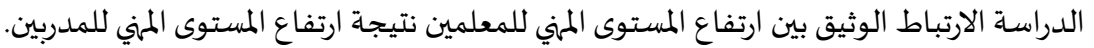

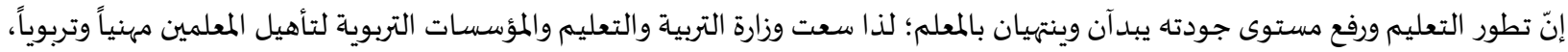

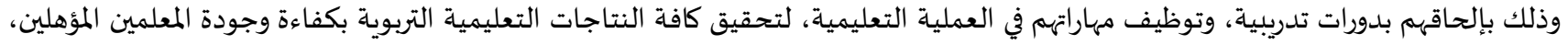

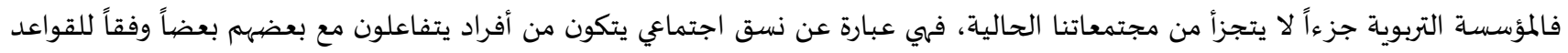

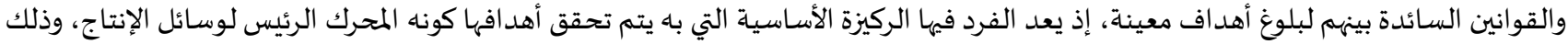

عبر المهام والوظائف الموكلة له (Al-Ajaz, Laouh \&Ashqar, 2010). وتعمل المؤسسات التعليمية على توفير فرص الإبداع والتميز، الذي يساهم في رفع أداء الموظفين وتطويرهم بالتوجيه الواعي، انطلاقاً من توفير

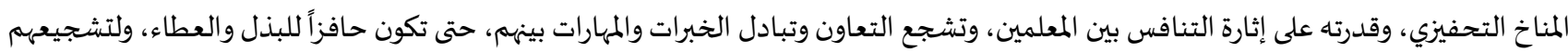

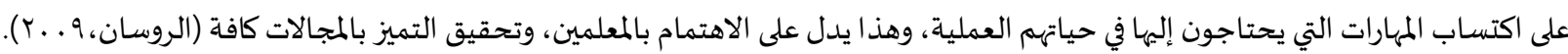

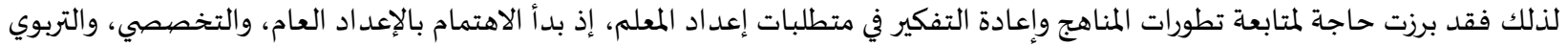

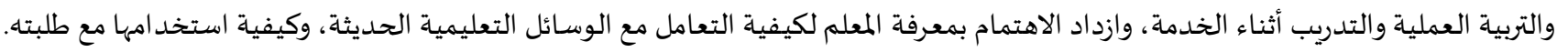

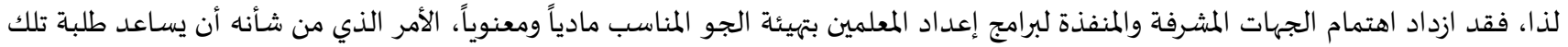

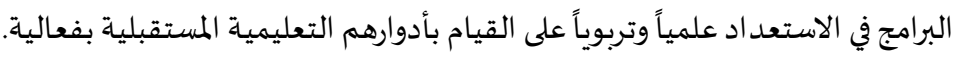

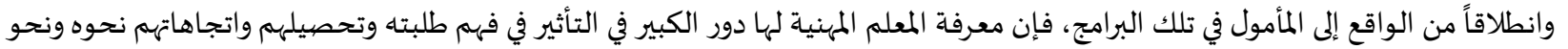

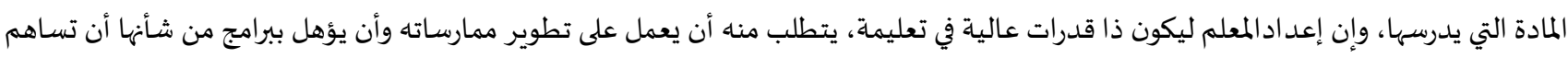

$$
\text { في تمام إعداده وتكوينه (الرويس، ع. . ب). }
$$

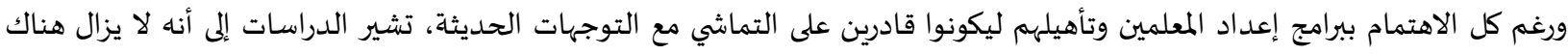

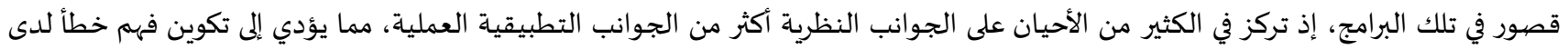

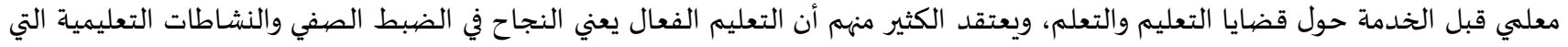

يقدمونها لطلبتهم، ويهمل هؤلاء أهمية الفهم العميق لموضيوع التخصص وكيفية تعليمه.(Loughran, Mulhall \& Berry, 2008, Hashweh, 2005).

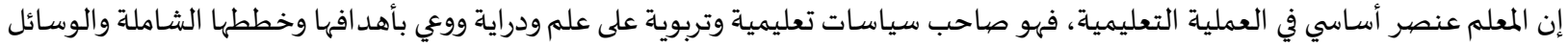

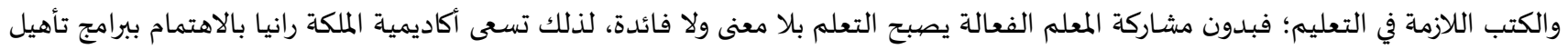

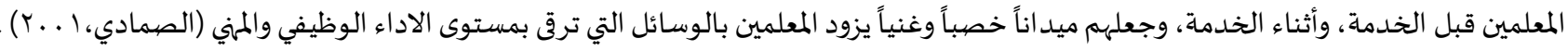

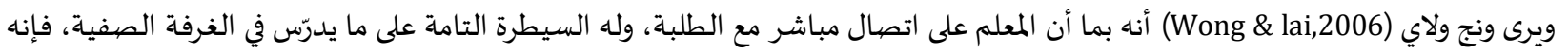

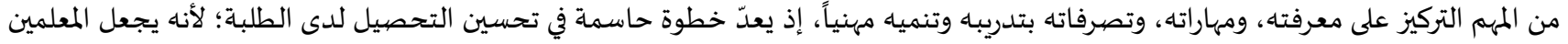

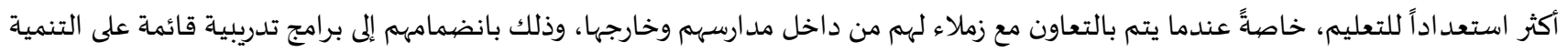

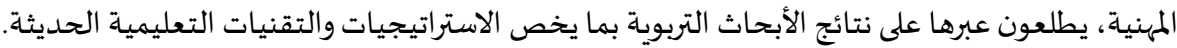

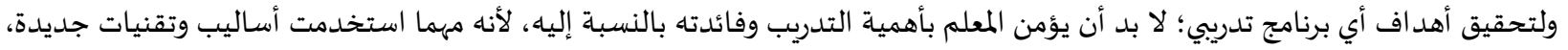

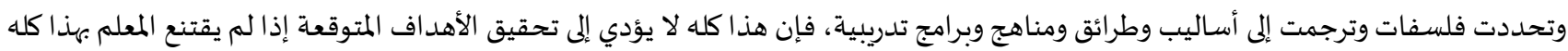

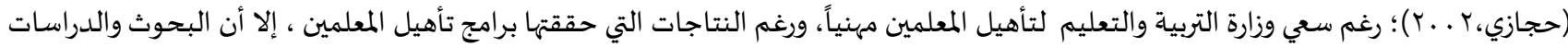

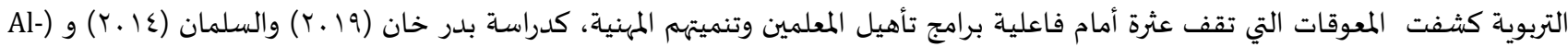
(Shibli, 2012

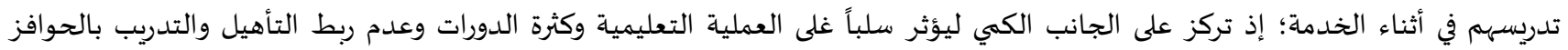

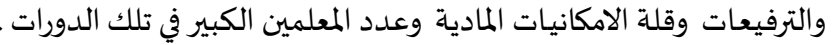

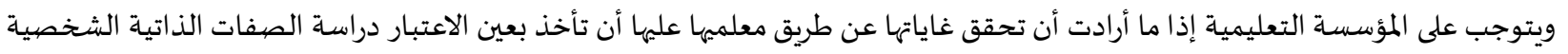

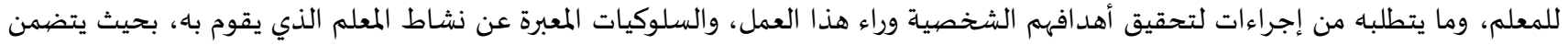

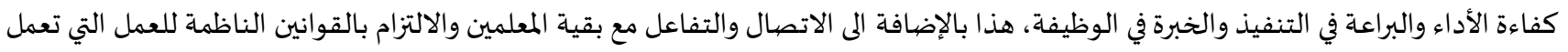

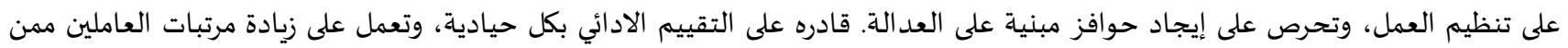

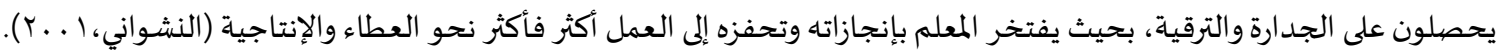


تعمل أكاديمية الملكة رانيا على تدريب وتأهيل المعلمين فهي مؤسسة رائدة في الأردن والمنطقة العربية في تدريب وتأهيل المعلمين، تأسست

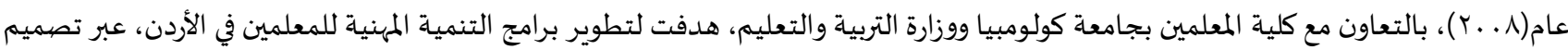
برامج تدريبية تواكب التطورات والمستجدات الحديثة في التعليم، عبر استراتيجيات وتقنيات تعليمية مستندةً إلى نتائج دراسات وأبحاث تربوية سابقة،

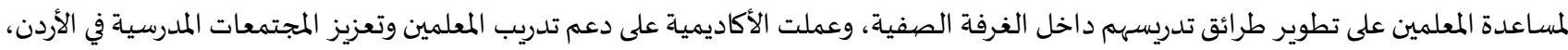
بدمج المعلمين في شبكات تدريبية يتبادل المعلمون فهها الخبرات، ويتباحثونّ في أنجح الاستراتيجيات والتقنيات التعليمياة، بحيث يستفيدون من تجارب

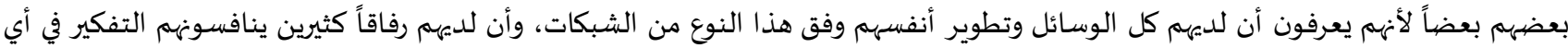
مشكلة يواجهونها ليسعوا جاهدين معاً على حلها، مثل الوصول إلى وسائل وأساليب وتقنيات تُلهم الطلبة وتحثهم على العمل معاً؛ مما يجعلهم مطالبين بالتفكير والسؤال والتساؤل(Q) (QRA, 2012). وتنفذ وزارة التربية والتعليم عبر قسم الإشراف، والإسناد والتدريب التربوي بالتعاون مع مؤسسة الملكة رانيا لتدريب المعلمين على العديد من

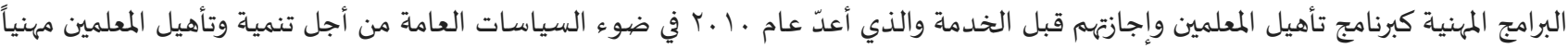

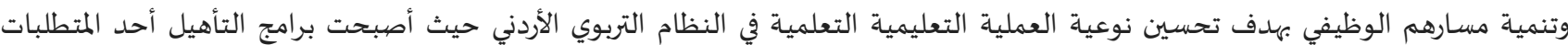

الاسـاسية للالتحاق بمهنة التعليم منذ عام II ـ الزيادة حوافز التعيين ومنح إجازة التعليم شريطة النجاح بالبرنامج (Ministry OF Education,2017).

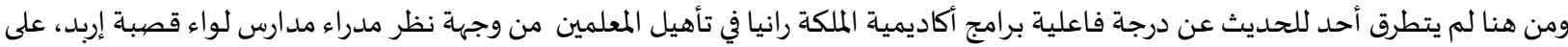

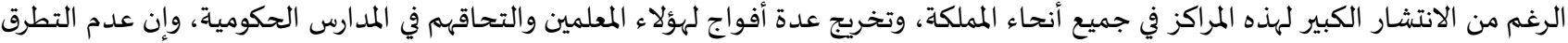

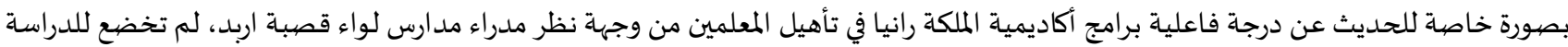
من قبل الباحثين، إذ ركزت الدراسات السابقة على الكفايات والبرامج التدريبية في إعداد المعلمين في مختلف التخصصيات، ولم يتركز الضوء على هذه

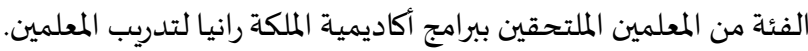
ولم تعثر الباحثة على حدّ علمها أي دراسة تناولت درجة فاعلية برامج أكاديمية الملكة رانيا في تأهيل المعلمين في الأردن بصورةٍ عامة، ومنطقة لواء

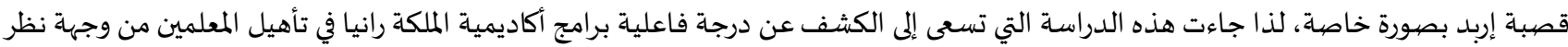
مدراء المدارس لواء قصببة إربد.

هدفت بدرخان (19 ـ إ) دراسة إلى التعرف إلى دور أكاديمية الملكة رانيا لتدريب المعلمين في تعزيز برامج التنمية المهنية للمعلمين في أثناء الخدمة في

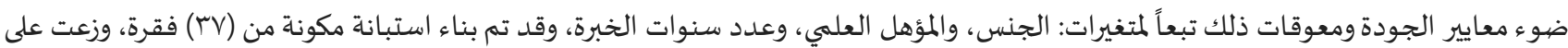

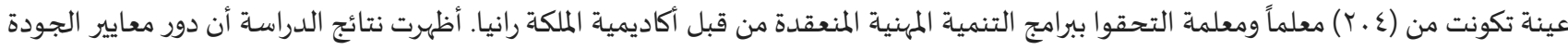
في تعزيز برامج التنمية المهنية للمعلمين تمثل في عقد دورات تدريبية مستمرة لمتابعة تطبيق وتنفيذ معايير الجودة في أداء المعلمين، في حين تمثل دور أكاديمية الملكة رانيا في تعزيز برامج التنمية المهنية في أثناء الخدمة في تشجيع المعلمين على تقبل المسؤولية عن نموهم المهني الموجه ذاتياً، وأن أبرز

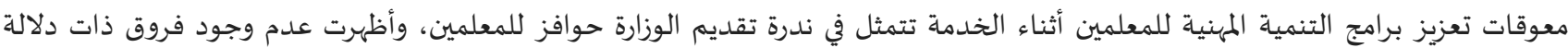

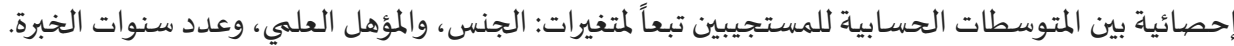

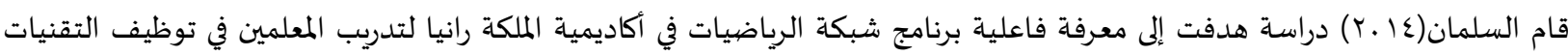
التعليمية من قبل معلمي الصفوف الثلاثة الأولى، وقد تكونت عينة الدراسة من (VY) معلماً ومعلمة من معلمي الصفوف الثلاثة الأولى والذين اجتازوا البرنامج التدريبي لشبكة الرياضيات من مديريات محافظتي الكرك والطفيلة. ولتحقيق أهداف الدراسة صمممت الباحثة ثلاث استبانات وقابلت ( ب ا)

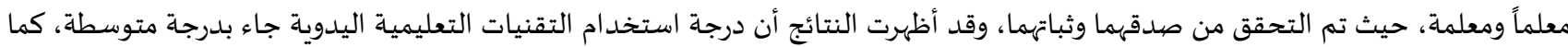
أظهرت وجود فروق ذات دلالة إحصائية عند مستوى الدلالة (1) (م=05) لدرجة استخدام التقنيات التعليمية اليدوية ففي تدريس الرياضيات ككل

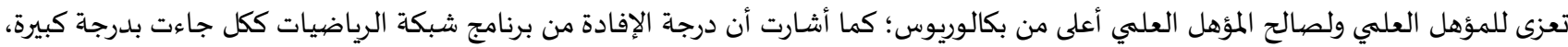
وعدم وجود فروق ذات دلالة إحصائية عند مستوى الدلالة (0.05= م) لدرجة الافادة من البرنامج تعزى للجنس والمؤهل العلمي والخبرة، وجاءت درجة

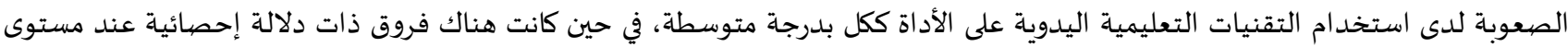
الدلالة (0.05 = م) لدرجة صعوبة استخدام التقنيات التعليمية اليدوية تعزى إلى متغير الجنس ولصالح الذكور ومتغير الخبرة ولصالح ذوي الخبرة

كما أجرى (AL-Shibli, 2012) دراسـة هدفت الى استقصاء أثر الجودة الشاملة في برامج التنمية المهنية للمعلمين من وجهة نظرهم تبعاً لمتغيرات

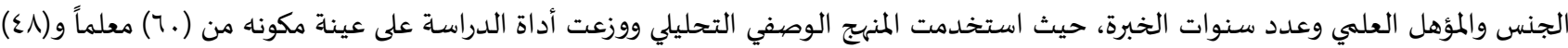
معلمة ، كما توصلت نتائج الدراسـة أن أغلب برامج التنمية المهنية قبل الخدمة تركز على الجانب الكمي لتؤثر في عملية التعليم وقلة الامكانات المادية في الوزارة وعدم منح المكافآت مالية وعدم ربطها بالترفيعات وأظهرت وجود فروق دالة احصيائيا تعزى لمتغيري المؤهل العلمي وعدد سنوات المبات الخبرة. 
هدفت دراسة البشارات والرمجي(r ا.ب) إلى تقصي الوضع القائم لبرامج إعداد وتأهيل المعلمين في الجامعات الفلسطينية وذلك من خلال

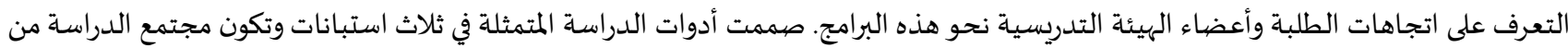

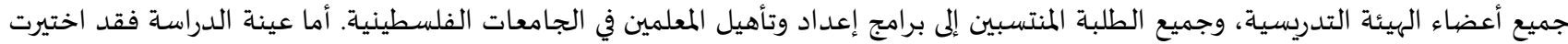
بالطريقة العشوائية البسيطة، كما أظهرت النتائج بأن هنالك قصور في هذه البرامجيع تمثل في جميع محاورها تقريبا مثل مخرجات التعلم المقصهودة، والمناهج و تقييم الطلبة، والتعليم والتعلم، وتقدم الطلبة، ومصادر التعلم، و ضمان الجودة وتحسينها. بينما ظهر أن لبعض المساقات إفادة كبرى

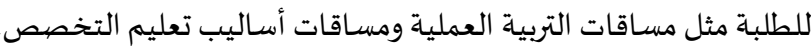
وأجرى وبستر (Webster,2005) دراسة هدفت إلى تطور أداء المعلمين خلال السنة الأولى من خدمتهم، وهي دراسة حالة، وتمت متابعة (11)

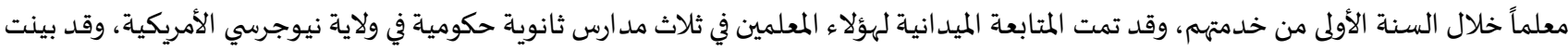
نتائج هذه الدراسة مدى الارتباط القوي بين الإطار التنظيمي للمدرسة والنمو المهني للمعلمين في السنة الأولى للخدمة. كما قام جوزيف (Joseph,2004) دراسة هدفت إلى تدريب معلمي العلوم بولاية جورجيا الأمريكية على كيفية وضيع خطة تدريس العلوم للطلاب،

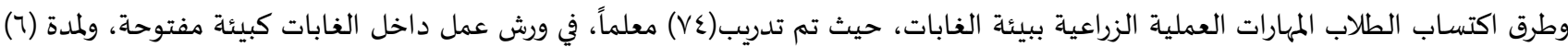

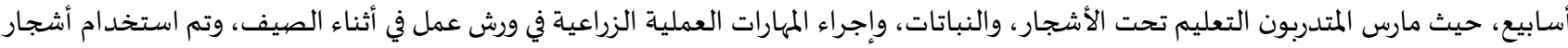

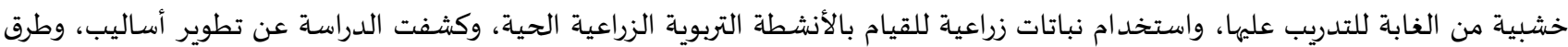
التدريس لدى المعلمين في تدريس العلوم، وتحسين مستوى أداء المهارات العملية الزراعية للأشجار الخشبية، ونباتات الغابة. اعتمدت الدراسات الأنفة الذكر على كشف درجة تطبيق البرامج التدريبية في تأهيل المعلمين في مختلف التخصصيات للمرحلتين الاساسية والثانوية كدراسة وبستر (Webster,2005) ومدى درجة امتلاكهم للكفاءات التعليمية حيث لوحظ أغلهها تتفق بوجود علاقة ارتباطية بين البرامج

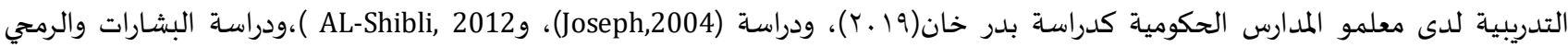

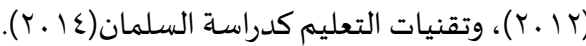

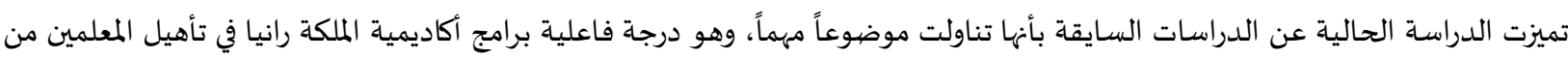

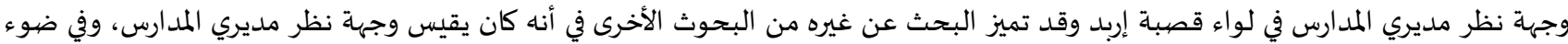

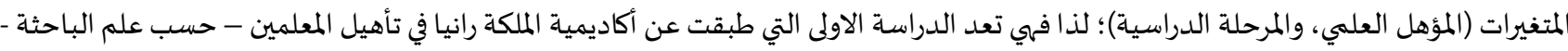
،وهذه الاضافة النوعية التي يمكن لهذه الدراسة أن تقدمها للإنتاج الفكري العربي المنشور في المجال. كما تشير الباحثة الم أهها أفادت من الدراسات السابقة في تنظيم الدراسة على نحو عام، وتحديد المنهجية الملائمة للدراسة، وفي إعداد الأداة ومجالاتها وفقراتها، ومناقشة النتائج وعرضها، مهية والتوصيات.

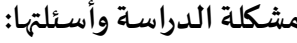
تتحدد مشكلة الدراسة في التعرف على درجة فاعلية برامج أكاديمية الملكة رانيا في تأهيل المعلمين من وجهة نظر مديري المدارس في لواء قصببة إربد، وذلك من خلال الاجابة عن السؤالين الآتيين:

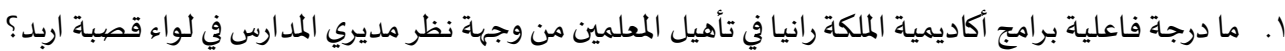

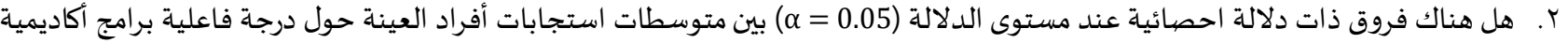

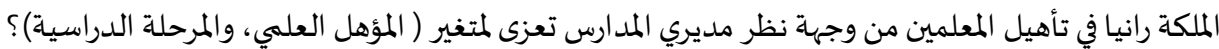

أهداف الدراسة: تهدف الدراسة في الكشف عن:

1. أ درجة فاعلية برامج تأهيل المعلمين في أكاديمية الملكة رانيا.

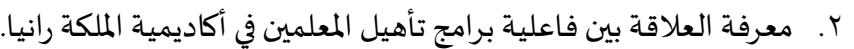

أهمية الدراسـة:

تتبع أهمية هذه الدراسة من أهها تسلط الضوء على موضوع بارز من مواضيع المؤسسات التعليمية وهي برامج أكاديمية الملكة رانيا في تأهيل

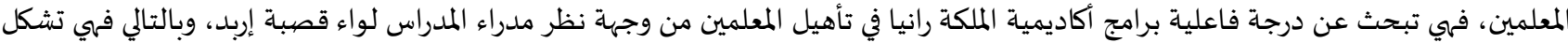
مساهمة مهمة من أجل تحديد الآثار المتترتبة على فاعلية برامج أكاديمية الملكة رانيا. 
وتتركز أهمية الدراسة في أهها تسلط الضوء على جانبيين أساسيين:

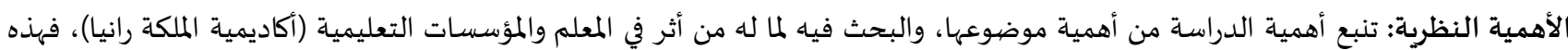

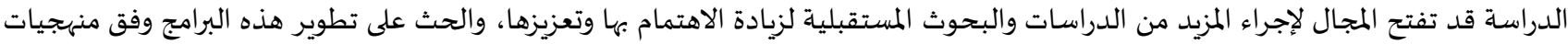

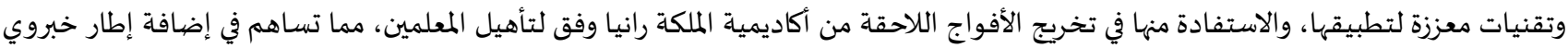

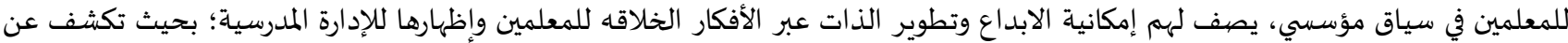

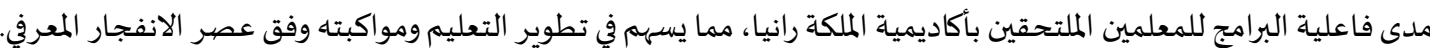

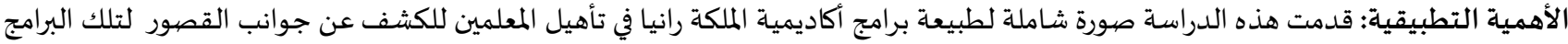

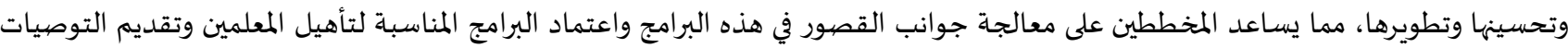

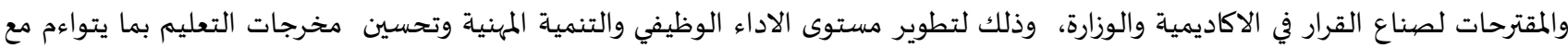

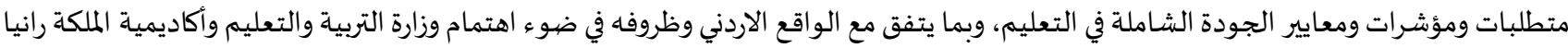

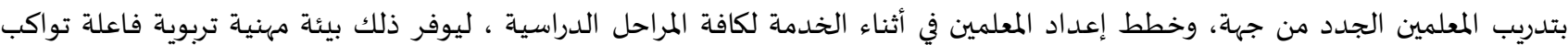

مصطلحات الدراسة:

اشتملت المصطلحات والمفاهيم الأساسية المتعلقة بهذه الدراسة على ما يأتي: الفاعلية: هي إحدى معايير قياس نجاح المنظمات في تحقيق أهدافها والوصول إلى غاياتها، وبلوغ رسالتها والالتزام برؤيتها والتمسك فيها

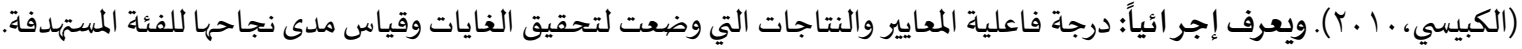

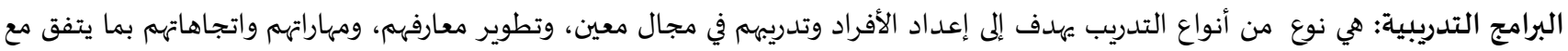

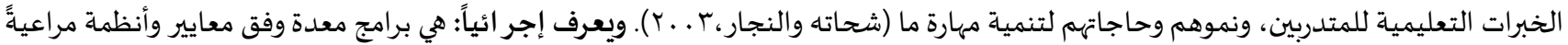
الخصائص السيكومترية للأفراد وفق مجالات متعددة لتحسينهم وتطويرهم نحو الأفضلئ.

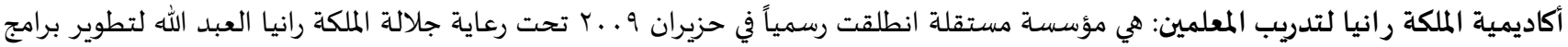

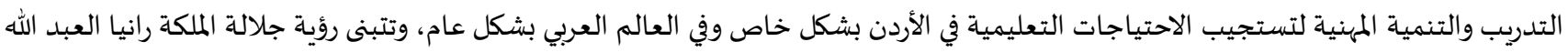

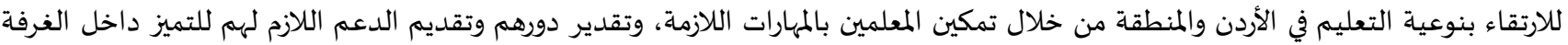
الصفية(Queen Rania Teacher Academy Website). تأهيل المعلمين: مجموعة برامج تدرببية خاصة لتأهيل المعلمين في المؤسسات التعليمية لتحسين الأداء الممني حيث يساعد الفرد في مهنته بالحصول على مزيد من المين

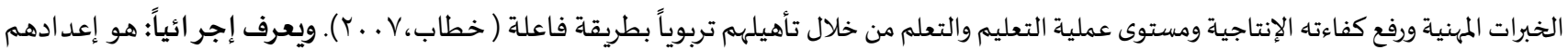

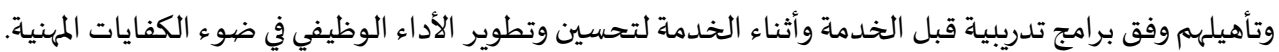
الحدود البشرية: اقتصر تطبيق الدراسة على مديري المدارس الحكومية في لواء قصبة اربد، والبالغ عددهم ( . 7) مديرة.

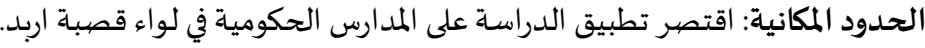

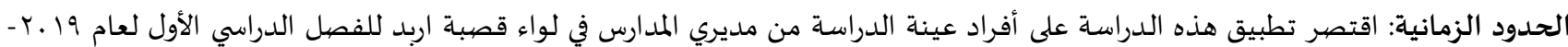
.Y. T.

الحدود الموضوعية: ستقتصر هذه الدراسة على خصائص أدوات الدراسة ومدى استجابة عينة الدراسة، وستعمل الباحثة على تطوير الاستبيان وتوزيعها على عينة الدراسة

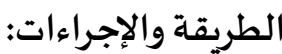
منهجية الدراسة: اعتمدت هذه الدراسة المنهج الوصفي الارتباطي، وذلك لوصف وتحليل وتفسير نتائج استجابات أفراد عينة الدراسة، والمنهج الارتباطي لمعرفة العلاقة الارتباطية بين درجة فاعلية برامج أكاديمية الملكة رانيا. 
تكون مجتمع الدراسة من جميع مديري المدارس العاملين في مديرية التربية والتعليم التابعة للواء قصببة إربد والبالغ عددهم (. (Y) مديراً ومديرة

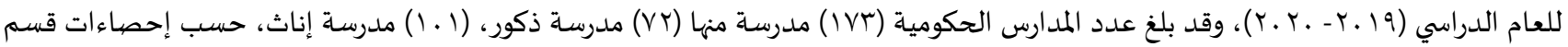

التخطيط في مديرية تربية وتعليم لواء قصبة إربد. عينة الدراسة: تم اختيار عينة ممثلة لمجتمع الدراسة بالطريقة العشوائية البسيطة من مجتمع الدراسة الكلي، تم توزيع (.7) استبانة من مديري المدارس عشـوائياً في لواء قصببة إربد. أداة الدراسـة: ولتحقيق أهد اف الدراسة تم الاعتماد على أداة رئيسية لجمع المعلومات اللازمة، وهي:

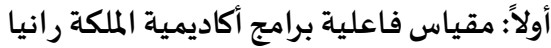
تم تطوير استبانة فاعلية البرامج أكاديمية الملكاة رانيا، وذلك بعد الإطلاع على الدراسات والأبحاث ذات العلاقة كدراسة بدر خان (19 .ب)،

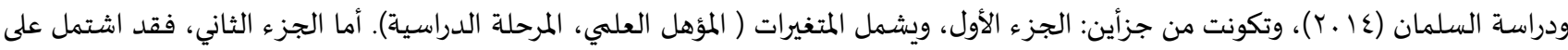
(§§) فقرة موزعة على أربعة مجالات وهي: الخطط الدراسية والأهداف، الخدمات الإدارية المساندة في توظيف تكنولوجيا التعليم، الرقابة والمتابعة والتقويم، الشراكة مع المجتمع. صيدق الاستبانة: (فاعلية برامج أكاديمية الملكة رانيا): للتحقق من مؤشرات صهدق الاستباندانة، تم إجراء ما يلي: أولاً: الصبدق الظاهري (صداق المبدة: المحكمين):

للتأكد من صددق محتوى استبانة الدراسة تم عرضها على مجموعة من المحكمين من ذوي الاختصاص والخبرة من أعضاء هيئة التدريس في قسم الادارة التربوية و قسم علم النفس التربوي وقسم المناهج والتدريس في الجامعات الحكومية والخاصة ومجموعاة من مشرفي التربويين في أكاديمية الملكاة رانيا ومديرية التربية والتعليم للواء قصببة اربد البالغ عددهم (10) محكماً؛ وذلك لإبداء آرائهم وملحوظاتهم وتعديلاتهم من حيث مدى سلامة الصياغة

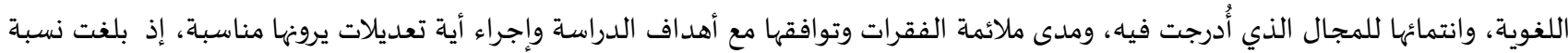

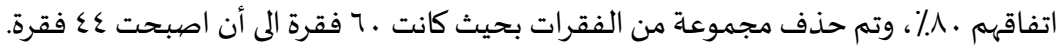
صدل البناء:

لاستخراج دلالات صدق البناء للمقياس، استخرجت معاملات ارتباط فقرات المقياس مع الدرجة الكلية في عينة استطلاعية من خارج عينة

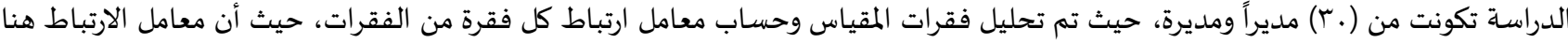

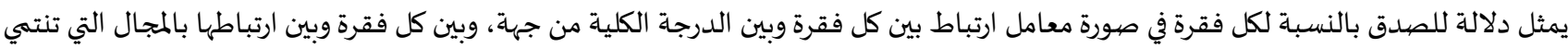

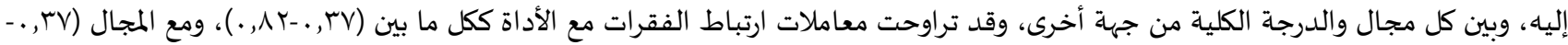

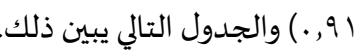

جدول( ) : معاملات الارتباط بين الفقرات والدرجة الكلية والمجال التي تنتهي إليه

\begin{tabular}{|c|c|c|c|c|c|c|c|c|}
\hline معامل الارتباط & معامل الارتباط & رقم الفقرة & معامل الارتباط & مع مع المجال الارتباط & رقم الفقرة & معامل الأرتباط & معامل الارتباط & رقم الفقرة \\
\hline **., 09 & **., 77 & ri & **., \&А & ${ }^{* *} ., 0$. & 17 & ${ }^{* *} ., \vee \varepsilon$ & **.,人 & 1 \\
\hline **., 09 & ${ }^{* *} ., v$. & rr & $* * ., 0$. & **., TV & IV & $* * ., \vee\urcorner$ & $* * ., \Lambda$ & r \\
\hline **., ๆ. & $* * ., 09$ & rr & **., 01 & $* * ., 70$ & 11 & $*_{.}^{*}, \varepsilon r$ & $* * ., \leqslant 0$ & $r$ \\
\hline${ }^{* *} ., \vee$. & $* *, V r$ & $r \varepsilon$ & $*_{.}^{*}, T V$ & **., IV & 19 & ${ }^{* *},, \vee \vee$ & $* * ., \wedge \vee$ & $\varepsilon$ \\
\hline **., 01 & $* * ., \vee$. & ro & $* * ., 7$ & **.,or & $r$. & **., ᄉr & $* * ., 91$ & 0 \\
\hline **.,Tr & $* * ., V r$ & $r y$ & $* * ., 07$ & $* *, V \varepsilon$ & rI & **., $\vee 9$ & $* * ., \wedge \vee$ & 7 \\
\hline **., o \{ & ${ }^{* *} ., \vee \backslash$ & rv & **., Oᄉ & $* * ., \varepsilon \wedge$ & rt & $* ., \leq 0$ & $* * ., 0$. & v \\
\hline$*_{.}^{*}$, rᄉ & *., rV & ru & **. , 79 & **., $\vee\urcorner$ & r & $* * ., \wedge$ & **., 91 & $\wedge$ \\
\hline$* * ., \mathrm{oV}$ & **., or & rq & $*_{*}^{*}, \leq \varepsilon$ & $* *, 7$. & $r \varepsilon$ & $*^{* *}, 0 \leq$ & $* * .,\urcorner \wedge$ & 9 \\
\hline$*_{.}, \leqslant 7$ & **.,TY & $\varepsilon$. & $* ., \leq 7$ & $*_{.}, \leq 0$ & ro & ${ }^{*} ., \leq \varepsilon$ & $*^{*}, \varepsilon_{0}$ & 1. \\
\hline$*_{.}, \varepsilon Y$ & **., Tr & «1 & ${ }^{* *} ., \mathrm{VI}$ & **., Tr & Y & $*_{.,}^{*}, 1$ & $*_{.,}^{*}, 0$ & 11 \\
\hline **., or & $* * .,\{\wedge$ & $\varepsilon r$ & **., ov & **.,or & TV & ${ }^{* *},, V r$ & **., NY & Ir \\
\hline$*_{.}^{*}, \varepsilon r$ & $* * ., 00$ & $\varepsilon r$ & $* *, 7$. & $* * ., 79$ & $r \Lambda$ & $* * ., \leqslant \varepsilon$ & **., or & ir \\
\hline$* *, 0$ & $* * ., 77$ & $\varepsilon \varepsilon$ & $* * ., V \varepsilon$ & ${ }^{* *} ., \mathrm{V} V$ & rq & ${ }^{* *} ., V Y$ & $* * ., 10$ & $1 \varepsilon$ \\
\hline & & &., 00 & $* * ., 0 \leqslant$ & $r$. & $* * ., \varepsilon \wedge$ & $* ., r V$ & 10 \\
\hline
\end{tabular}

(2* دالة إحصائياً عند مستوى الدلالة (1 . , ).

* دالة إحصائياً عند مستوى الدلالة (0. . . .). 
جدول (Y): معاملات الارتباط بين المجالات ببعضها والدرجة الكلية

\begin{tabular}{|c|c|c|c|c|c|}
\hline فاعلية برامج أكاديمية & الشر اكة مع المجتمع & الرقابة والمتابعة & المسنولندة في توظيف الإدارية & الخطط الدراسية & \\
\hline & & & & 1 & الخطط الدراسية والأهداف \\
\hline & & & 1 & * & التعليم \\
\hline & & 1 & **., VIr & 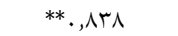 & الرقابة والمتابعة والتقويم \\
\hline & 1 & ${ }^{* *},, \vee \wedge \varepsilon$ & $*_{*}^{*}$, , $1 \leqslant 9$ & **., (Tा & الشراكة مع المجتمع \\
\hline 1 & 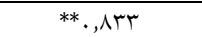 & $*_{* *}^{*}, 9 \leqslant \wedge$ & **., V9८ & $*_{* *}^{*}, 9$, & فاعلية برامج أكاديمية الملكة رانيا \\
\hline
\end{tabular}

* دالة إحصائياً عند مستوى الدلالة (0. ., .). **دالة إحصائياً عند مستوى الدلالة (1 . . .).

ثبات أداة الدراسـة:

للتأكد من ثبات أداة الدراسة، فقد تم التحقق بطريقة الاختبار وإعادة الاختبار (test-retest) بتطبيق المقياس، واعادة تطبيقه بعد أسبوعين على مجموعة من خارج عينة الدراسة مكوّنة من (.ץ)، ومن ثم تم حساب معامل ارتباط بيرسون بين تقديراتهم في المرتين.

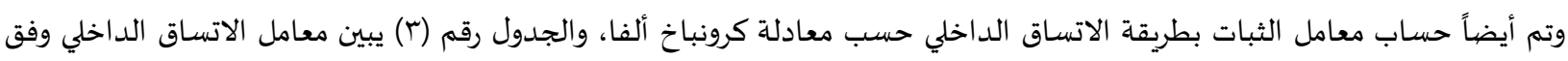
معادلة كرونباخ ألفا وثبات الإعادة للمجالات والأداة ككل واعتبرت هذه التهات القيم ملائمة لغايات هذه الدراسة. جدول (ץ): معامل الاتساق الداخلي كرونباخ ألفا وثبات الإعادة للمجالات والدرجة الكلية

\begin{tabular}{|c|c|c|}
\hline الاتساق الداخلي & 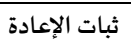 & 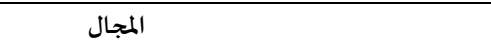 \\
\hline.,$\Lambda$ & . 94 & الخطط الدراسية والأهداف \\
\hline$\cdot, \vee \varepsilon$ &., 19 & الخدمات الإدارية المساندة في توظيف تكنولوجيا التعليم \\
\hline$\cdot, \wedge \varepsilon$ &., 91 & الرقابة والمتابعة والتقويم \\
\hline$\cdot, \mathrm{V}$ & $\cdot, 19$ & الشراكة مع المجتمع \\
\hline ., $9 \varepsilon$ & . 94 & فاعلية برامج أكاديمية الملككة رانيا \\
\hline
\end{tabular}

السؤال الاول: ما درجة فاعلية برامج أكاديمية الملكة رانيا في تأهيل المعلمين من وجهة نظر مديري المدارس في لواء قصبة إربد؟

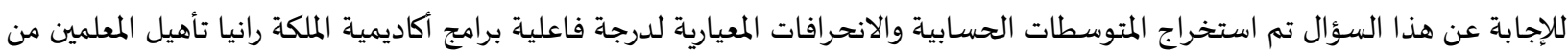
وجهة نظر مديري المدارس في لواء قصبة إبربد، والجدول أدناه يوضح ذلك.

جدول (ع): المتوسطات الحسابية والانحر افات المعيارية لدرجة فاعلية برامج أكاديمية الملكة رانيا في تأهيل المعلمين من وجهة نظر مديري المدارس في لواء

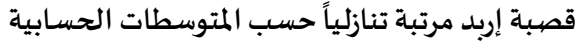

\begin{tabular}{|c|c|c|c|c|c|}
\hline 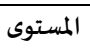 & الانحراف المعياري & المتوسط الحسابي & 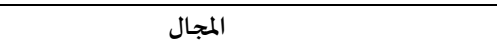 & 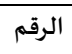 & 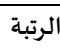 \\
\hline 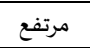 & . $7 \leqslant 0$ & $r, \wedge \varepsilon$ & الخطط الدراسية والأهداف & 1 & 1 \\
\hline متوسط & $\cdot, \wedge \cdot \vee$ & $r, 0$. & الخدمات الإدارية المساندة في توظيف تكنولوجيا التعليم & r & r \\
\hline متوسط & .,Vro & $r, r_{\Lambda}$ & الرقابة والمتابعة والتقويم & $r$ & $r$ \\
\hline متوسط &., $09 \mathrm{~V}$ & $r, 10$ & الشراكة مع المجتمع & $\varepsilon$ & $\varepsilon$ \\
\hline متوسط & צTT, & $r, 01$ & 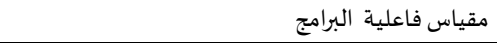 & & \\
\hline
\end{tabular}

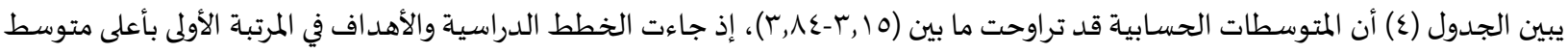

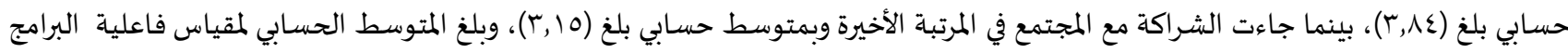
ككل (1,0)، وتعزو ذلك إلى أن الأكاديمية التي التحق بها الطلاب المعلمون حققت لهم فرص الاستفادة من الحوافز المادية والمعنوية وفرص الترقيه المعاديه

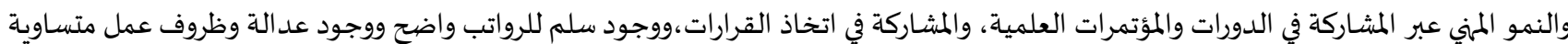
للجميع بغض النظر عن الرتبة الأكاديمية ويوجد سلم رواتب واضح.

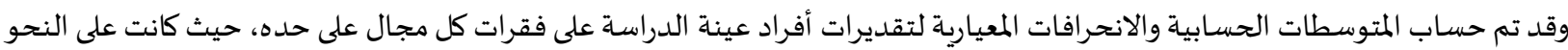


المجال الأول: الخطط الدراسية والأهداف

جدول (ه): المتوسطات الحسابية والانحر افات المعيارية المتعلقة بالخطط الدراسية والأهداف مرتبة تنازلياً حسب المتوسطات الحسابية

\begin{tabular}{|c|c|c|c|c|c|}
\hline 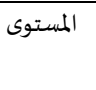 & 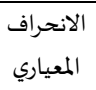 & الحسابي - المتوسط & 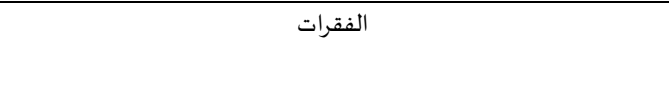 & 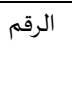 & 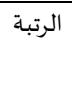 \\
\hline مرتفح & $\cdot, \wedge \wedge 7$ & $\varepsilon, 1 V$ & تكسب الأهداف المعلمين الخبرات الميدانية اللازمة لإعدادهم للحياة العملية. & $\varepsilon$ & 1 \\
\hline مرتفع & ו & $\varepsilon, \cdot V$ & والتكنولوجية المعاصية الملكةة رانيا الخطط الدراسية البرامج والمستجدات العلمية & r & 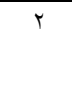 \\
\hline 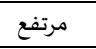 & $\cdot, \mathrm{AVr}$ & $\varepsilon, . Y$ & تكسب الأهداف المعلمين قيم انفتاح الحوار ومهارات التواصل مع الآخرين. & 7 & r \\
\hline 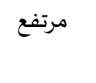 & $\cdot, 10 \varepsilon$ & $\varepsilon, . r$ & تحمل مسؤولية تعلمهيم. & 11 & $r$ \\
\hline 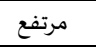 & $\cdot$, A.r & $r, 9 \mathrm{~V}$ & تتصف الخطط الدراسية بالحداثة والمرونة والأصالة. & 1. & 0 \\
\hline 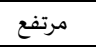 & $\cdot, \lambda r \mid$ & r,q4 & تحقق الخطط والأهداف مبدأ ديمقراطية التعليم. & v & 1 \\
\hline مرتفع & , vor & $r, q$. & المستقبلية من خلامج أكاديمية الملكة رانيا لتحقاضيا الواضحة. & 1 & $\mathrm{~V}$ \\
\hline 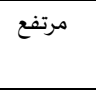 & $\cdot, \mathrm{VVV}$ & $r, 10$ & التقديم أكاديميثة الملكة رانيا أنشطة فاعلة لتوظيفها وفق استراتيجيات & $1 \varepsilon$ & $\wedge$ \\
\hline 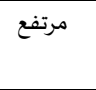 & $\cdot, \mathrm{\vee} 99$ & $r, 10$ & تحفز برامج أكاديمية الملكة رانيا بتأدية العمل في المدرسة بالتجديد والبعد & 17 & $\wedge$ \\
\hline 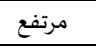 & , ^ $\varepsilon$ & r,A. & تكسب أهداف البرنامج المعلمين المقدرة على التفكير العلمي، والتعلم الذاتي. & $\circ$ & 1. \\
\hline 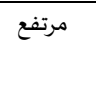 &., 911 & $r, \Lambda$. & في الميدان. & ir & 1. \\
\hline 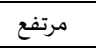 & $\cdot$, vNr & r,VT & تشمل الخطط في الأكاديمية أهدافاً، ومضامين واضحة ومحددة. & 9 & ir \\
\hline متوسط &., $\mathrm{V} Y \mathrm{q}$ & $r, \mathrm{TV}$ & توازن الخطط والأهداف بين أنشطة التعليم والبحث والتطوير. & $\wedge$ & ir \\
\hline 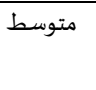 & $\cdot, \wedge 17$ & r,TY & تدالابتكمار. أكاديمية الملكة رانيا المعلم المتميز في تحقيق أعلى مستويات الإبداع & 10 & ir \\
\hline متوسط & $1, .77$ & $r, 0$. & تراعي برامج الأكاديمية في خططها واقع البيئة المحيطة للطلبة. & $r$ & 10 \\
\hline متوسط & $1, . \leqslant 9$ & $r, \varepsilon V$ & وتعملم برامج أكاديمية الملكة رانيا بالصعوبات التي يواجهها المعلم والطلبة & ir & 17 \\
\hline مرتفع & . $7 \leqslant 0$ & $r, \wedge \varepsilon$ & الخطط الدراسية والأهداف & & \\
\hline
\end{tabular}

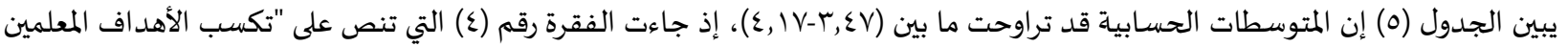

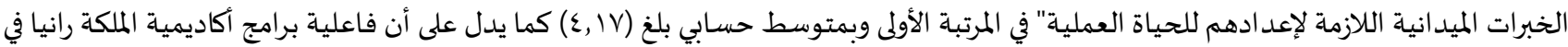
تأهيل المعلمين بشكل فعال بتوظيف مقررات الدراسة، واستخدام وسائل التكنولوجيا التي تعزز العملية التعليمية والربط بين النشاطات التعليمة

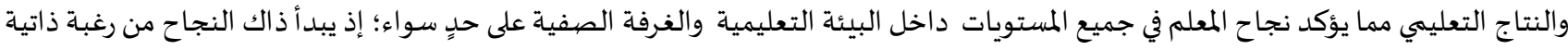
للمعلم بأن يكون مبدعاً ومبتكراً وقد يعزى ذلك إلى وجود اتساق بين فاعلية برامج أكاديمية الملكة رانيا واحتياجات المعلمين لتأهيلهم وفق المستويات

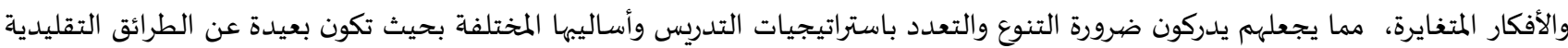

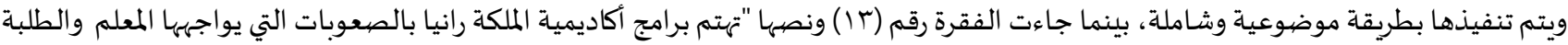

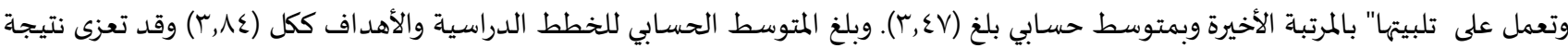
ذلك إلى الظروف المادية الصعبة، وضعف الميزانية المخصصية لتوظيف مواد تعليمية متنوعة وذلك لازدحام المقررات الدراسية بالمعلومات النظرية

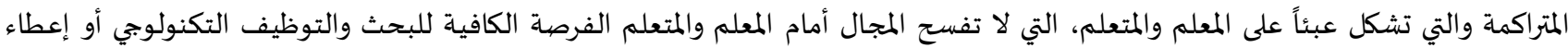
منشورات ومطبوعات ووسائل داعمة غير تلك المقررة في المناهج الدراسية وأن الإمكانات المادية للمدرسة والوزارة غير مساعدة في تطبيق ما يتعلماه

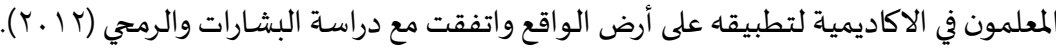


المجال الثاني: الخدمات الإدارية المسـاندة في توظيف تكنولوجيا التعليم

جدول (7): المتوسطات الحسابية والانحر افات المعيارية المتعلقة بالخدمات الإدارية المساندة في توظيف تكنولوجيا التعليم مرتبة تنازلياً حسب المتوسطات الحسابية

\begin{tabular}{|c|c|c|c|c|c|}
\hline المستوى & الانحراف المعياري & المتوسط الحسابي & الفقرات & الرقم & الرتبة \\
\hline مرتفع &., , 79 & $r, v$. & تدورب أكاديمية الملكة رانيا الكوادر البشرية على استخدام شبكات المعلومات والاتصال & iv & 1 \\
\hline متوسط & $\cdot, \Lambda \Sigma \wedge$ & $r, \imath$. & تطور أكاديمية الملككة رانيا الأداء الوظيفي للمعلمين بشكل دوري ومستمر. & r. & r \\
\hline متوسط & . A9Y & r,or & تسههم الورش التدرببية في الأكاديمية لمواكبة التطور المعرفي والتقني، وتوظيف نظه & re & r \\
\hline متوسط & $1, .11$ & $r, 0$. & توظلف برامج أكاديمية الملكة رانيا سياسة أساليب لتوفير الوقت والجهد أثناء تأدية & rI & $\varepsilon$ \\
\hline متوسط & .999 & $r, \varepsilon V$ & والنوفر أكاديمية الملكة رانيا مصادر تعلم متعددة بالمستوى المطلوب من ناحية الكم & 14 & . \\
\hline متوسط & $1, .15$ & $r, \varepsilon$. & الانتاجية. & rr & 7 \\
\hline متوسط &., 901 & $r, \mathrm{ru}$ & توفر أكاديمية الملككة رانيا المرافق التعليمية والتجهيزات اللازمة لاستخدام التكنولوجيا & 19 & $\mathrm{v}$ \\
\hline متوسط & $\cdot, \lambda \cdot V$ & $r, 0$. & الخدمات الإدارية المساندة في توظيف تكنولوجيا التعليم & & \\
\hline
\end{tabular}

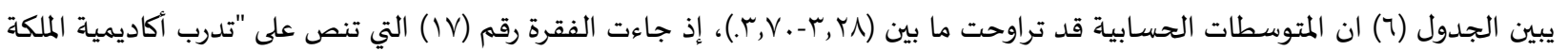
رانيا الكوادر البشرية على استخدام شبكات المعلومات والاتصال ومواقع التواصل الاجتماعي" في المرتبة الأولى وبمتوسط حسابي بلغ (. (Y,V)، بينما جاءت الفقرة رقم (9 1) نصها "توفر أكاديمية الملكة رانيا المرافق التعليمية والتجهيزات اللازمة لاستخدام التكنولوجيا الحديثة في الإدارة والتعليم" لماتئ

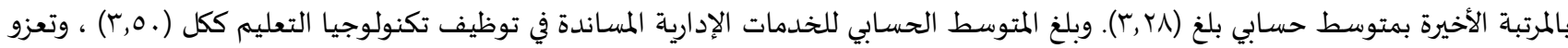
الباحثة بتأثر الهوية الوظيفية للمعلمين بالتغيرات التي تطرأ على العملية التعليمية، والتي قد تتعارض مع رغبات المبات المعات المعلمين وتجاربهم أو ممارساتهم

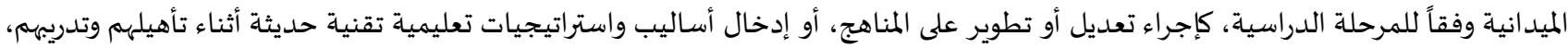
مما يشعرهم بالقلق والارتباك؛ وبالتالي التأثير على مدى ثبات الهوية الوظيفية ووضوحها، ومن ثم اضطرابها، وذلك لان وزارة التربية والتعليم لا توفر

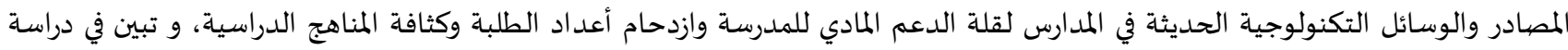
السلمان (ع ا ب) وجود فروق في درجة استخدام التقنيات التعليمية اليدوية جاء بلدرجة متوسطة، وأن استخدام التقنيات التعليمية اليدوية في

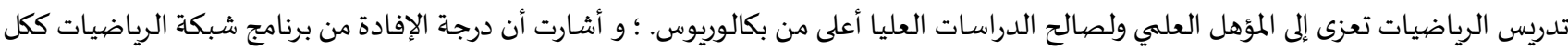
جاءت بدرجة كبيرة، وعدم وجود فروق لدرجة الافادة من البرنامج تعزى للجنس والمؤهل العلمي والخبرة، وجاءت درجة الصعوبة لدى استخدام

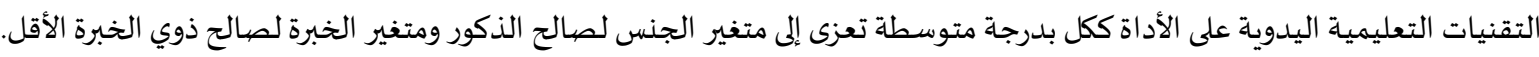

المجال الثالث: الرقابة والمتابعة والتقويم

جدول (V): المتوسطات الحسابية والانحر افات المعيارية المتعلقة بالرقابة والمتابعة والتقويم مرتبة تنازلياً حسب المتوسطات الحسابية

\begin{tabular}{|c|c|c|c|c|c|}
\hline 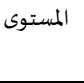 & 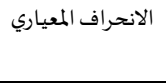 & المستوسط - ابي & 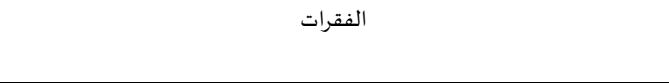 & 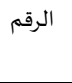 & الرتبة \\
\hline 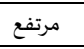 & $\cdot, 9 \varepsilon \wedge$ & $r, \eta \Lambda$ & يطبق المعلمين ملاحظات المدير والمشرفين في أثناء التدربب في الميدان. & $r r$ & 1 \\
\hline متوسط & $1, .90$ & r,ov & تحفز أكاديمية الملكة رانيا المبدعين وتكافؤهم. & ry & r \\
\hline متوسط &., $9 \Lambda \mathrm{r}$ & $r, 00$ & تتصف القيادة الإدارية في الأكاديمية، بالأمانة والعدالة والنزاهة والشفافية. & $r \cdot$ & $r$ \\
\hline متوسط & $1, \ldots$ & $r, 0$. & تملهم برامج أكاديمية الملكة رانيا بتعزيز نقاط القوة ومعالجة نقاط الضعف لدى بلدية & $r$ & $\varepsilon$ \\
\hline متوسط &., $9 \wedge \mathrm{r}$ & $r, \varepsilon \wedge$ & تدعم برامج أكاديمية الملكة رانيا بتأدية الأعمال بطريقة صحيحة، وخالية من & $r \varepsilon$ & $\circ$ \\
\hline متوسط & $\cdot, 974$ & $r, \varepsilon r$ & واؤادي نظام الرقابة والمتابعة في أكاديمية الملككة رانيا لرفع الجوانب المهنية & $r \varepsilon$ & 7 \\
\hline متوسط & $1, .9 \varepsilon$ & $r, \varepsilon r$ & أكاديمية الملكلة رانيا. & rr & $\mathrm{v}$ \\
\hline متوسط &., 994 & $r, \mathrm{ru}$ & ترسخ برامج أكاديمية الملكة رانيا مبادئ الموضوعية والمساءلة والشفافية. & ro & $\wedge$ \\
\hline متوسط & $1, .1$. & $r, r \Lambda$ & تطوضوعية (الكفاءة والفاعلية والجودة والإنتاجية). & r & $\wedge$ \\
\hline متوسط & l, Irr & r, ro & تقييم أكاديمية الملكة رانيا خريجها بمعايير صادقة وموضوعية في أثناء الخدمة. & rV & 1. \\
\hline متوسط & $1,11 Y$ & $r, \varepsilon V$ & يظهر نظام الرقابة والمتابعة جوانب الهدر التربوية بالأكاديمية. & rq & 11 \\
\hline متوسط & ., Vro & $r, r \Lambda$ & الرقابة والمتابعة والتقويم & & \\
\hline
\end{tabular}




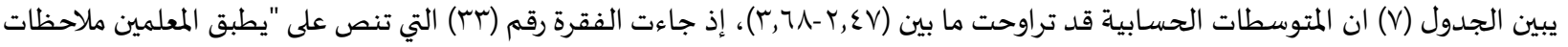

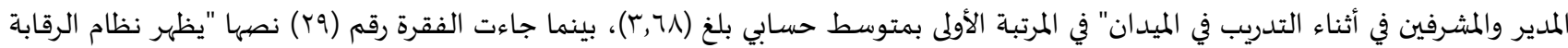
والمتابعة جوانب الهدر التربوية بالأكاديمية" بالمرتبة الأخيرة وبمتوسط حسابي بلغ (Y), (Y). وبلغ المتوسط الحسابي للرقابة والمتابعة والتقويم ككل

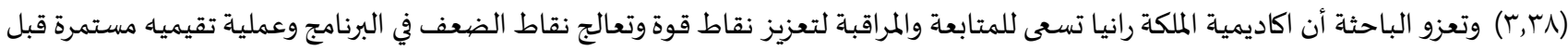

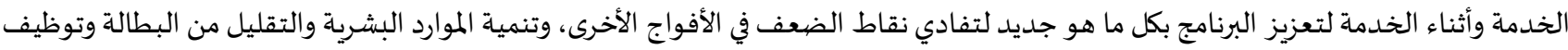

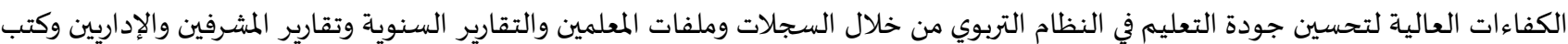

الشكر والتقدير . الشماء.

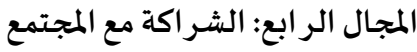

جدول (^): المتوسطات الحسابية والانحر افات المعيارية المتعلقة بالشر اكة مع المجتمع مرتبة تنازلياً حسب المتوسطات المسات

\begin{tabular}{|c|c|c|c|c|c|}
\hline 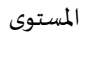 & 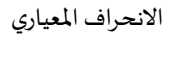 & المسابي - المتوسط & 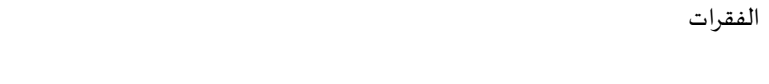 & 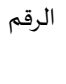 & الرتبة \\
\hline 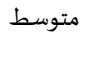 &., 9.1 & $r, 7 r$ & تلمجتمق أكاديمية الملكة رانيا خريجها بمواقع العمل ليصبحوا على مقربة من الواقع اليومي & ru & 1 \\
\hline 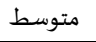 & $1, .17$ & $r, \varepsilon \vee$ & تُوفر برامج الاكاديمية قنوات الاتصال بينها وبين المؤسسات العامة والخاصة. & ro & r \\
\hline متوسط & , AVI & $r, \varepsilon r$ & تبأسلوب فعال لأداء المهام. & $\varepsilon$. & $r$ \\
\hline متوسط & . VE & $r, \varepsilon r$ & تسهم برامج أكاديمية الملكة رانيا بتنسيق العمل مع الجهات المختلفة الداخلية والخارجية. & $\varepsilon r$ & $\varepsilon$ \\
\hline متوسط & $\cdot$, Aro & r, r ו & تلحبط بين فعاليات ونواتج المؤسسات العلمية وبين احتياجات وتطلعات الأكاديمية & $\varepsilon \varepsilon$ & 0 \\
\hline متوسط &., $9 \varepsilon$ & $\Gamma, \Gamma \Lambda$ & تشجع وتحفز للاهتمام بالبحوث التطبيقية والإجرائية التي تخدم قضايا المجتمع. & ry & 7 \\
\hline متوسط & $1, .91$ & r,IT & تضع نتائج البحوث التي تجريها في خدمة المجتمع والعملية التعليمية التعلمية. & re & $\mathrm{v}$ \\
\hline 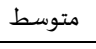 &., 901 & $r, \mathcal{M}$ & يشارك المعلم في العمل خارج أوقات الدوام الرسمي لأداء المهمة المطلوب تنفيذها. & rq & $\wedge$ \\
\hline متوسط & 1,rrr & r,Vr & يواجه المعلمين مشكلات مع زملاء العمل يعيق منافستهم في الأكاديمية. & « & 9 \\
\hline 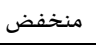 & . ג & $r, 1 \Lambda$ & تساهم برامج أكاديمية الملكة رانيا في تعزيز التوافق المني بين أفراد العمل. & $\varepsilon r$ & 1. \\
\hline متوسط &., $09 \mathrm{~V}$ & $r, 10$ & الشراكة مع المجتمع & & \\
\hline
\end{tabular}

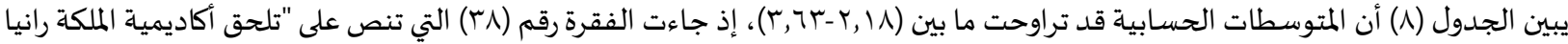

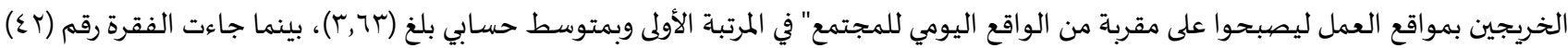
نصها "تساهم برامج أكاديمية الملكة رانيا في تعزيز التوافق المهني بين أفراد العمل" بالمرتبة الأخيرة وبمتوسط حسابي بلغ (1/, (Y). وبلغ المتوسط الحسابي

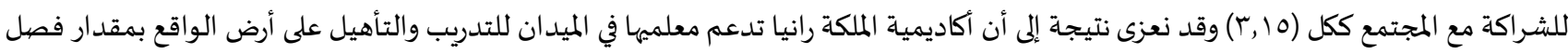
دراسي لاكتساب الخبرات وتبادل الكفاءات وتعزيز نقاط القوة ومعالجة نقاط الضعف لديهم، وتنمية البحث العلمي وتحفيزهم لحل المشكلات والقدرة

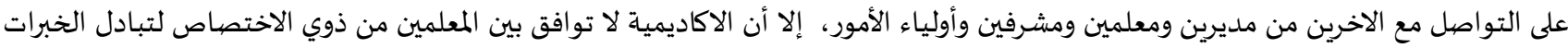
والكفاءات والتعلم المستمر بل تخلق روح المنافسة وحب الذات من مدين والطموح للوصول إلى القماة، لذلك تتحفظ بأعمالهم وبحوثهم العلمية بسرية مطلقة

وتامة لغايات المصداقية والشفافية لمشاركيها واتفقت مع دراسة (Al-Shibli,2012).

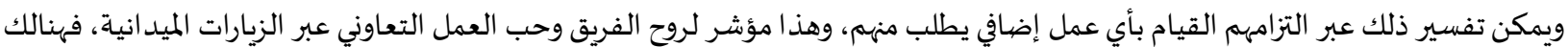
عوامل تنظيمية تتعلق بالتنظيم ذاته وما يسوده من أوضاع وعلاقات وظيفية ترتبط بالعمل والعامل؛ من هذه العوامل: الرضا عن نظم وأساليب

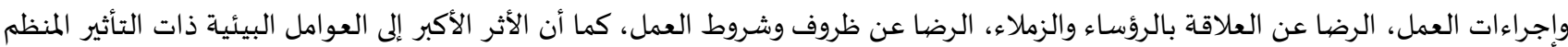
على المعلم، بالصورة الني تؤثر في رضاه عن عمله؛ من هذه العوامل: الانتماء الاجتماعي، ونظرة الادارة إلى المعلم، ومدى تقديره لدوره، وما يسود هذاء الدها

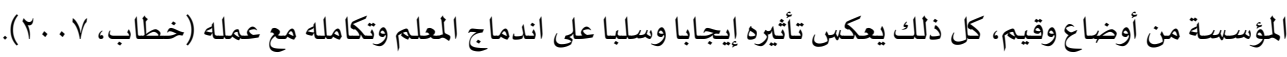

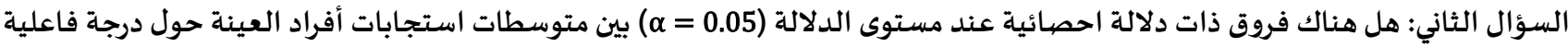
برامج أكاديمية الملكة رانيا في إعداد وتأهيل المعلمين من وجهة نظر مديري المدارس تعزى لمتغيري (المؤهل العلمي، والمرحلة الدراسية)؟

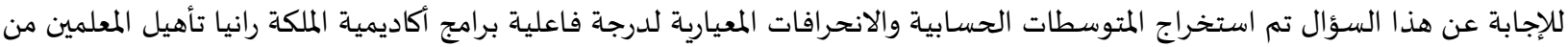
وجهة نظر مديري المدارس حسب متغيري والمؤهل العلمي، والمرحلة الدراسية، والجدول أدناه يوضح ذلك. 


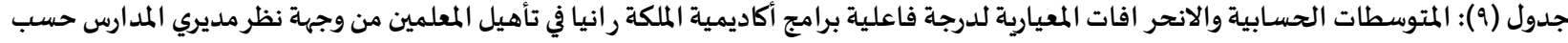
متغيري المؤهل العلمي، والمرحلة الدراسية

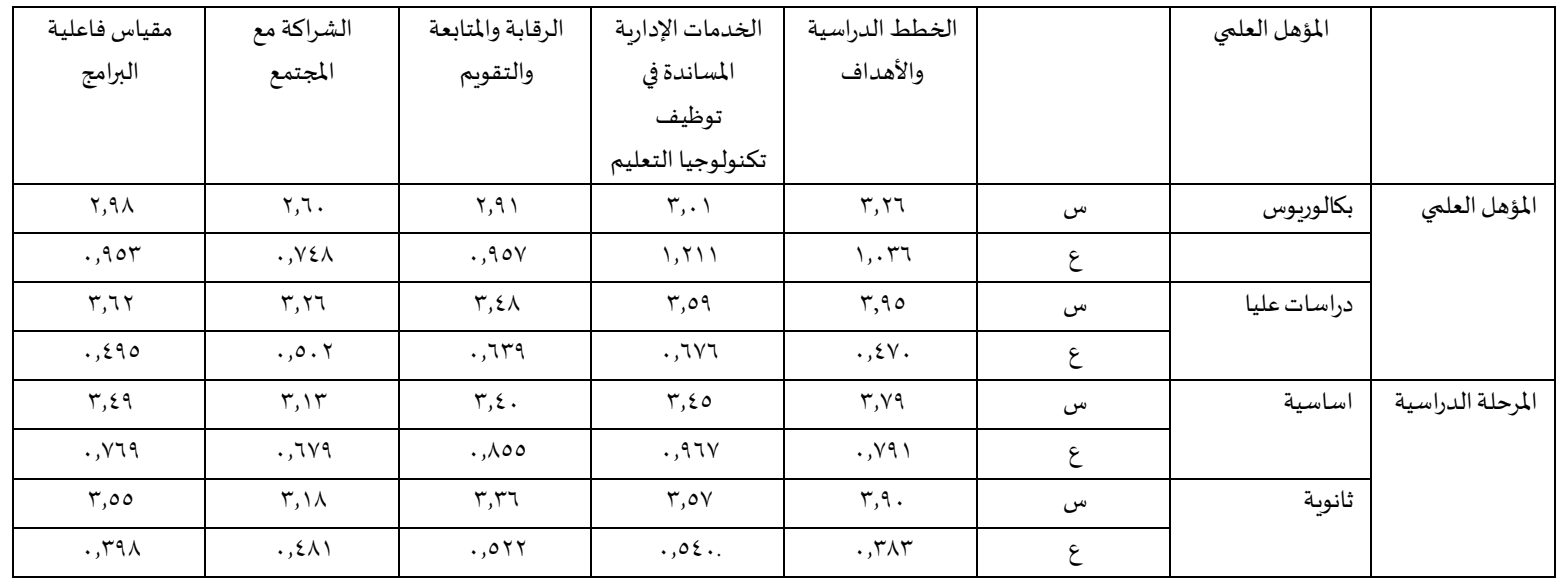

س= المتوسط الحسابي ع=الانحراف المعياري

يبين الجدول (9) تبايناً ظاهرياً في المتوسطات الحسابية والانحرافات المعيارية لدرجة فاعلية برامج أكاديمية الملكة رانيا في تأهيل المعلمين من وجهة نظر مديري المدارس بسبب اختلاف فئات متغيرات المؤهل العلمي، والمرحلة الدراسية. ولبيان دلالة الفروق الإحصائية بين المتوسطات الحسابية تم استخدام تحليل التباين الثنائي المتعدد على المجالات جدول ( ـ () وتحليل التباين

الثنائي للأداة ككل جدول (11) (1).

جدول ( ـ 1): تحليل التباين الثلاثي المتعدد لأثر المؤهل العلهي، والمرحلة الدراسية على المجالات

\begin{tabular}{|c|c|c|c|c|c|c|}
\hline ال الإحصائية & قيمة ف & مت المربعات & 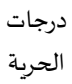 & مجموع المربعات & المجالات & مصددر التباين \\
\hline.,$\ldots r$ & $1 ., \Lambda \Gamma \varepsilon$ & r,ANT & 1 & $r, \wedge \wedge T$ & الخطط الدراسية والأهداف & المؤهل العلمي \\
\hline.,.$\varepsilon r$ & $\varepsilon$, ז V & $r, 701$ & 1 & $r, 701$ & تكنولوجيا التعليم الإدارية المساندة في توظيف & هوتلنج= qrr, . \\
\hline.,.+1 & $0,7 V r$ & T,A.T & 1 & T,A.T & الرقابة والمتابعة والتقويم & $\ldots, \ldots=\tau$ \\
\hline$\ldots 1$ & $11,9 \cdot V$ & $r, 7 r$. & 1 & r,tr. & الشراكة مع المجتمع & \\
\hline$\cdot, V \varepsilon$. &., 111 &.,.$\varepsilon$ & 1 &.,.$\varepsilon$. & الخطط الدراسية والأهداف & المرحلة - الة \\
\hline$\cdot, \vee \vee$. &., 111 &., .79 & 1 &., .79 & تكنولوجيا التعليم الإداية المساندة في توظيف & هوتلنج=0 ؛ ـ., \\
\hline . &.,$Y 09$ &., $1 \Gamma \Lambda$ & 1 &., $1 Y \Lambda$ & الرقابة والمتابعة والتقويم & $\cdot, 77 \cdot=\tau$ \\
\hline \multirow[t]{9}{*}{., $9 V r$} & $\ldots, \ldots 1$ &.,$\ldots$ & 1 & $\ldots$ & الشراكة مع المجتمع & \\
\hline & &., 409 & or & $r ., \leqslant \leqslant 0$ & الخطط الدراسية والأهداف & الخطأ \\
\hline & & ( & or & $r 0,010$ & تكنولوجيا التعليم الإدارية المساندة في توظيف & \\
\hline & &.,$\leqslant 9 \varepsilon$ & or & ru, 10 . & الرقابة والمتابعة والتقويم & \\
\hline & &.,$\Gamma \cdot 0$ & or & IV,rvo & الشراكة مع المجتمع & \\
\hline & & & 09 & $T \varepsilon, O T \varepsilon$ & الخطط الدراسية والأهداف & 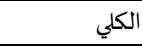 \\
\hline & & & 09 & 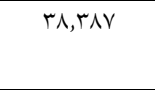 & تكنولوجيا التعليم الإدارية المساندة في توظيف & \\
\hline & & & 09 & $r ., q \vee V$ & الرقابة والمتابعة والتقويم & \\
\hline & & & 09 & $r 1, . \leqslant 9$ & الشراكة مع المجتمع & \\
\hline
\end{tabular}

يتبين من الجدول (· (1) الآتي:

وجود فروق ذات دلالة إحصائية (م=0.05 م)تعزى لأثر المؤهل العلمي في جميع المجالات وجاءت الفروق لصالح الدراسات العليا. عدم وجود فروق ذات دلالة إحصائية (م=0.05) تعزى لأثر المرحلة الدراسية في جميع المجالات. 
جدول (1 ( ): تحليل التباين الثنائي لأثر المؤهل العلمي والمرحلة الدراسية على درجة فاعلية برامج أكاديمية الملكة رانيا في تأهيل المعلمين من وجهة نظر مديري

\begin{tabular}{|c|c|c|c|c|c|}
\hline \multicolumn{6}{|c|}{ المدارس } \\
\hline الدلالة الإحصائية & قيمة ف & متوسط المربعات & درجات الحرية & مجموع المربعات & مصدر التباين \\
\hline.,$\ldots r$ & $9, \leq 0$. & $r, r \varepsilon$ & 1 & $r, r \varepsilon$ & المؤهل العلمي \\
\hline., $9 \vee r$ & $\ldots, \ldots 1$ & $\ldots$ & 1 & $\ldots$ & المرحلة التي يدرسها المعلم \\
\hline & & . ror & ov & $r ., 1 \leqslant \Lambda$ & الخطأ \\
\hline & & & 09 & $r r, 0 \leqslant \lambda$ & الكلي \\
\hline
\end{tabular}

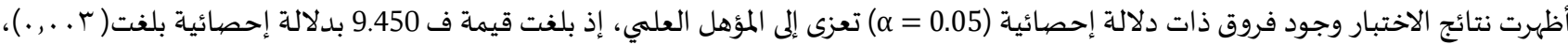

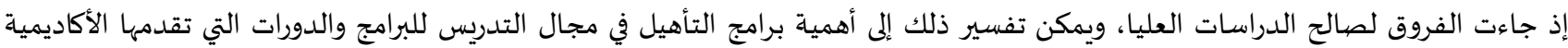
لمعلميها كافة بغض النظر عن مؤهلاتهم العلمية فبرامج التأهيل تصقل شخصياتهم المهنية وتذيب الفروقات بينهم؛ لأها تركز بشكل رئيس على مختلف الجوانب المهنية والأد ائية. ويدل على أن جميع المعلمين لديهم القدرة من الاستفادة من فاعلية تلك البرامج في تطوير أدائهم المهني والأكاديمي، وأظهرت

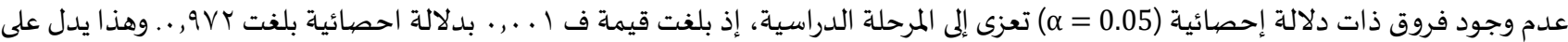

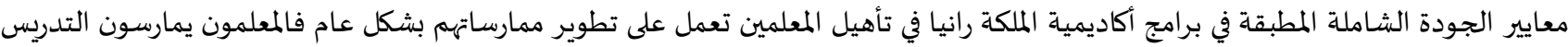

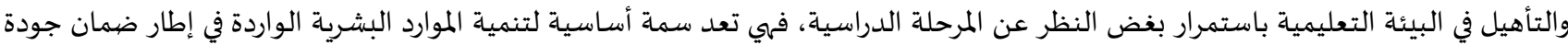

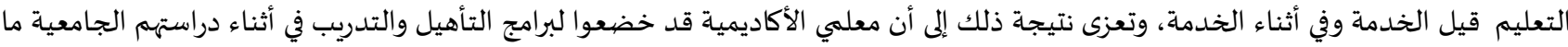

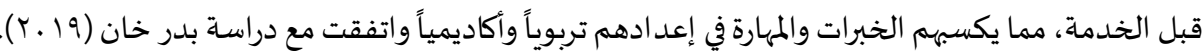

في ضوء نتائج الدراسة الحالية، فإنها توصي بـ: ضرورة إجراء المزيد من البحوث حول فاعلية برامج أكاديمية الملكة رانيا في تأهيل المعلمين. التوسع في ربط نظام ترقية المعلمين باستمرارهم في البحث والدراسة والتنمية المهنية، للاستفادة من برامج الاكاديمية مع إصدار قوانين وتشريعات تلزم المعلمين بالتطبيق. توفير الدعم المادي والمعنوي لمعلمي أكاديمية الملكة رانيا أثناء الخدمة من قبل وزارة التربية والتعليم لتفعيل كفاءاتهم على أرض الواقع.

ا. بدر خان، سوسن. (19 ـ ب). "دور أكاديمية الملكة رانيا لتدريب المعلمين في تعزيز برامج التنمية المهنية للمعلمين في أثناء الخدمة في ضوء معايير

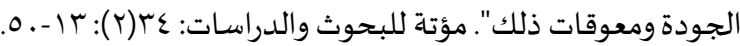

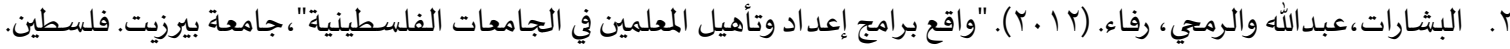

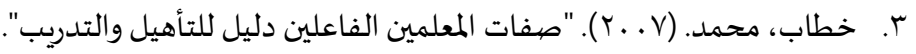
ع. حجازي،وجياء. (r . .ب). "تحديد الاحتياجات التدريبية لمعلمي الرياضيات في المدارس الحمكومية في محافظات شمال فلسطين". رسالة ماجستير غير منشورة. جامعة النجاح الوطنية. فلسطين. 0. داوود، أمان. (ع ا ـ ب). "مستوى الفاعلية التربوية لبرنامج تأهيل معلمي المرحلة الأسـاسية الدنيا أثناء الخدمة من وجهة نظرهم وعلاقته باتجاهاتهم نحو مهنة التدريس. رسالة ماجستير. كلية الدراسات العليا. جامعة النجاح الوطنية. فلسطين.

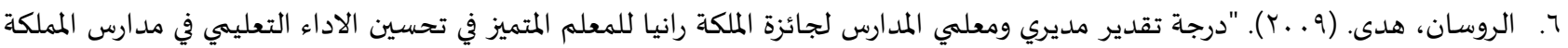
الاردنية الهاشمية". رسالة دكتوراه جامعة اليرموك. الاردن.

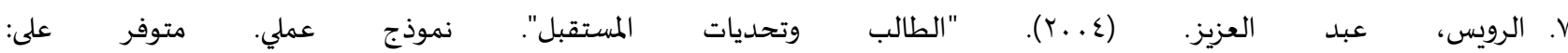
http://www.almarefh.org/news.php?action=listnewsm\&offset=992\&id=2

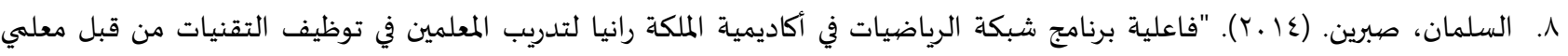
الصفوف الثلاثة الأولى". رسالة ماجستير. كلية التربية. جامعة اليرموك. الأردن. 9. شحاته، حسن والنجار، زينب. (ץ . . (Y). معجم المصطلحات التوبوية والنفسية. القاهرة : دار المصرية اللبنانية. 


$$
\begin{aligned}
& \text { • ا. الصمادي، وائل. ( ا . ب). "درجة رضا معلمي برامج تأهيل المعلمين لدرجة البكالوريوس في جامعة اليرموك عن البرنامج نفسـ". رسالة ماجستير } \\
& \text { غير منشورة. جامعة اليرموك. الاردن. } \\
& \text { 1 ا. عفاش، يحيى. (199). "الكفايات التعليمية التي يحتاجها المعلمون/ المعلمات في برامج التأهيل التربوي أثناء الخدمة كما يراها الملتحون بهذه }
\end{aligned}
$$

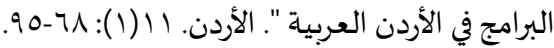

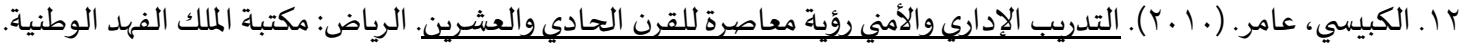

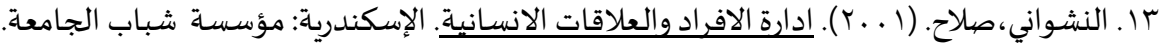

$$
\text { ثانياً: المراجع الأجنبية: }
$$

[1] Al- Ajaz, F., Laouh, E., \& Ashqar, Y. (2010). "The Real Status of Training Teachers of the Secondary Stage During Service", Journal of the Islamic University of Humanitarian Studies, 18 (2): 1- 59.

[2] Al-Shibli, E. (2012). "The Effect of TQM in Teacher Professional Development Programmes (The Experiment of UNRWA Jordan)", Damascus University Journal, 26 (4): 437-484.

[3] Frank, Ruth A (2007). "An Investigation Into the effectiveness of the trainer's model for in service science professional development programs or elementary", the university of taxas AAT $992791 \mathrm{~N}$, Umi pro Quest dessertaion full citation.

[4] Hashweh, M. (2005). "Teacher pedagogical constructions: A reconfiguration of pedagogical content knowledge". Teachers and Teaching: Theory and Practice, 11 (3): 273-292, https://doi.org/10.1080/13450600500105502.

[5] Joseph, W.J. (2004). "Georgia Environmental Network in Education”. Agricultural Education Activities, www.Georgia arches.uga. edu. (6-9-2007).

[6] Loughran, J., Mulhall, P.\& Berry, A. (2008). "Exploring Pedagogical Content Knowledge in Science Teacher Education", International Journal of Science Education, 30(10): 1301-1320.

[7] Ministry of Education. (2017). "Educational Development Project towards Knowledge Economy Phase II", the Hashemite Kingdom of Jordan, and Available on the link :

[8] Queen Rania Teacher Academy Website (QRTA). (N.D), The Hashemite Kingdom of Jordan, Available on the link: http://www.qrta.edu.jo./, http://www.moe.gov.jo/Projects/ProjectMenuDetails.aspx?MenuID=1 \& ProjectID=2.

[9] Webster Thomas J (2005). "First Year Teacher Their Evolution from Pre-Service to The End of Irst Year of Practice in The Context of Organizational", frames AAT 9973932 N, Umi pro Quest desertion full citation.

[10] Wong,T. and Lai, C.(2006). "Exploring Factors Affecting Mathematics Teaching Effectiveness among Pre-service Primary Mathematics Student -Teachers". The Hong K ONG Institute of Education. Available at: http://www.aare.edu.av/06pap/won06754.pdf retrieved on 5/4/2010. 
المجلة الدولية للدراسـات التربوية والنفسية

International Journal of Educational \& Psychological Studies (EPS)

Journal Homepage: https://www.refaad.com/views/EPSR/Home.aspx

www.refaad.com

\title{
The effectiveness of queen Rania's academy programs for teachers' rehabilitation from school principals' perspectives at Qasabt Irbid
}

\author{
1Shaim'a "Mohammed Ameen" Al-Dwery, ${ }^{2}$ Adnan Badri Alibrahim, ${ }^{3}$ Anis Saqer Khasawneh \\ ${ }^{1} \mathrm{PhD}$ student - Department of Administration and Fundamentals of Education, College of Educational Sciences, \\ Yarmouk University, Jordan \\ 2,3 Professor Doctor, Department of Administration and Fundamentals of Education, College of Educational \\ Sciences, Yarmouk University, Jordan \\ 1Shaimadwery123@yahoo.com
}

Received : 19/2/2020 Revised : 10/3/2020 Accepted : 19/3/2020 DOI : https://doi.org/10.31559/EPS2020.8.3.9

Abstract: The study aimed to identify the effect of Queen Rania's Academy programs in teachers' rehabilitation from schools' principals' perspectives at Qasabt Irbid in light of qualification, school level. A questionnaire was built, consisting of (44) item distributing on four domains: Curriculum and objectives; supportive administrative services in learning technology employment; monitoring, control, and evaluation; local community partnerships. The questionnaire was distributed to a sample totaling (60) female school principal after both validity and reliability were obtained. The results of the study indicated that curriculum and objectives ranked first $(\mathrm{m}=3.84)$ and that local community partnerships ranked last $(\mathrm{m}=3.15)$, while the means score for the effectiveness of the programs totals scale $(\mathrm{m}=3.51)$. The study found that there are statistically significant differences $(\alpha=0.05)$ due to qualifications in all the domains, in favor of higher education, while there were no statistically significant differences $(\alpha=0.05)$ due to school level in all domains, The study came out with a set of recommendations, the most prominent of which are: expanding the linking of the entertainment system for teachers to their continued research, study and professional development, to take advantage of the academic programs with the issuance of laws and legislations that obligate teachers to apply.

Keywords: Queen Rania's Academy Programs; Teachers Rehabilitation; School Principals; Qasabat Irbid.

\section{References:}

[1] 'fash, Yhya. (1991). "Alkfayat Alt'lymyh Alty Yhtajha Alm'lmwn/ Alm'lmat Fy Bramj Altahyl Altrbwy Athna' Alkhdmh Kma Yraha Almlthwn Bhdt Albramj Fy Alardn Al'rbyh ". Alardn. 11(1): 68-95.

[2] Bdr Khan, Swsn. (2019). "Dwr Akadymyh Almlkh Ranya Ltdryb Alm'lmyn Fy T'zyz Bramj Altnmyh Almhnyh Llm'lmyn Fy Athna' Alkhdmh Fy Dw' M'ayyr Aljwdh Wm'wqat Dlk". M'th Llbhwth Waldrasat: 34(2): 13-50.

[3] Albsharat,'Ebdallh Walrmhy, Rfa'. (2012). "Waq' Bramj E'dad Wtahyl Alm'lmyn Fy Aljam'at Alflstynyh". Jam't Byrzyt. Flstyn.

[4] Dawwd, Aman. (2014). "Mstwa Alfa'lyh Altrbwyh Lbrnamj Tahyl M'lmy Almrhlh Alasasyh Aldnya Athna' Alkhdmh Mn Wjht Nzrhm W'laqth Batjahathm Nhw Mhnt Altdrys. Rsalt Majstyr. Klyt Aldrasat Al'lya. Jam't Alnjah Alwtnyh. Flstyn.

[5] Hjazy,Wjyh. (2002). "Thdyd Alahtyajat Altdrybyh Lm'Imy Alryadyat Fy Almdars Alhkwmyh Fy Mhafzat Shmal Flstyn". Rsalt Majstyr Ghyr Mnshwrh. Jam't Alnjah Alwtnyh. Flstyn.

[6] Alkbysy, 'amr. (2010). Altdryb Aledary Walamny R'yh M'asrh Llqrn Alhady Wal'shryn. Alryad: Mktbt Almlk Alfhd Alwtnyh.

[7] Khtab, Mhmd. (2007). "Sfat Alm'Imyn Alfa'lyn Dlyl Lltahyl Waltdryb".

[8] Alnshwany,Slah. (2001). Adart Alafrad Wal'laqat Alansanyh. Aleskndryh: M'sst Shbab Aljam'h.

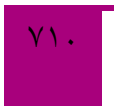


[9] Alrwsan, Hda. (2009). "Drjt Tqdyr Mdyry Wm'lmy Almdars Lja'zh Almlkh Ranya Llm'lm Almtmyz Fy Thsyn Alada' Alt'lymy Fy Mdars Almmlkh Alardnyh Alhashmyh". Rsalt Dktwrah Jam't Alyrmwk. Alardn.

[10] Alrwys, 'bd Al'zyz. (2004). "Altalb Wthdyat Almstqbl". Nmwdj 'mly. Mtwfr 'la: Http://Www.Almarefh.Org/News.Php?Action=Listnewsm\&Offset=992\&Id=2 $\quad$ Hrr Btarykh 30/1/2020.

[11] Shhath,Hsn Walnjar, Zynb. (2003). M'jm Almstlhat Altrbwyh Walnfsyh. Alqahrh: Dar Almsryh Allbnanyh.

[12] Alslman, Sbryn. (2014). "Fa'lyt Brnamj Shbkh Alryadyat Fy Akadymyh Almlkh Ranya Ltdryb Alm'lmyn Fy Twzyf Altqnyat Mn Qbl M'Imy Alsfwf Althlathh Alawla". Rsalt Majstyr. Klyh Altrbyh. Jam't Alyrmwk. Alardn.

[13] Alsmady, Wa'l. (2001). "Drjt Rda M'lmy Bramj Tahyl Alm'lmyn Ldrjh Albkalwryws Fy Jam't Alyrmwk 'n Albrnamj Nfsh". Rsalt Majstyr Ghyr Mnshwrh. Jam't Alyrmwk. Alardn. 